\title{
Consequences of Deficit Irrigation and Crop Load Reduction on Plant Water Relations, Yield, and Quality of 'Ambrosia' Apple
}

\author{
Denise Neilsen ${ }^{1}$ and Gerry Neilsen \\ Pacific Agri-Food Research Centre, Agriculture and Agri-Food Canada, \\ Summerland, BC VOH 1Z0, Canada
}

\author{
Sunghee Guak \\ Department of Horticulture, Chonbuk National University, Jeonju, 561-256, \\ Republic of Korea
}

Tom Forge

Pacific Agri-Food Research Centre, Agriculture and Agri-Food Canada, Summerland, BC VOH 1Z0, Canada

Additional index words. Malus $\times$ domestica M.9, drip irrigation, midday stem water potential, volumetric soil moisture content

\begin{abstract}
Uncertain water supplies resulting from changing climatic conditions in western North America led to this investigation of the role of crop load reduction in maintaining performance of high-density 'Ambrosia' apple (Malus $\times$ domestica) on M.9 rootstock. A split-plot experimental design was imposed for three growing seasons (200709) with six replicates of four main plot irrigation treatments and three crop load subplots comprised of three trees. Four season-long irrigation (Irr) treatments were applied through $2 \times 4 \mathrm{~L} \cdot \mathrm{h}^{-1}$ drip emitters per tree and included Irr1) control $[100 \%$ evapotranspiration (ET) replacement], Irr2) $50 \%$ ET replacement, Irr3) $50 \%$ ET replacement to half the emitters, and Irr4) an increasingly severe treatment commencing at $50 \%$ ET replacement (once every 2 days) in 2007 and progressing to $25 \%$ and $18 \%$ ET replacement, 2008-09. Three target crop loads were established annually, 4-5 weeks after bloom as low (2.5, 3, and 3.75), medium (4.5, 6, and 7.5), and high $(9,12$, and 15) fruit $/ \mathrm{cm}^{2}$ trunk cross-sectional area (TCSA) 2007-09, respectively, by hand thinning around 4 weeks after bloom. Volumetric soil moisture contents generally reflected the amount of water applied and ranged from $20 \%$ for control (Irr1) to $<\mathbf{1 0 \%}$ for Irr4. Both irrigation and crop load treatments affected midday stem water potential more than leaf photosynthesis and stomatal conductance $\left(g_{S}\right)$. By the 2 nd and 3rd year stem potential values for irrigation treatments ranged from a maximum of -1.0 to $-1.3 \mathrm{MPa}$ for Irr1 to minimums $\leq-2.0 \mathrm{MPa}$ for Irr4. $\mathrm{g}_{\mathrm{S}}$ decreased as midday stem potential decreased, but at any given stem potential value was greater at high crop loads, presumably in response to an increased demand for photosynthates. Fruit size decreased as crop load increased, but as irrigation deficits became more severe, fruit size was more closely correlated with stem water potential than $g_{\mathrm{S}}$. Consequently, fruit size was controlled by two mechanisms, competition for photosynthates and the effects of plant water status on $g_{s}$. Negative linear relationships between crop load and average fruit size were used to determine the crop load required to produce an average fruit size of $200 \mathrm{~g}$ at different irrigation deficits. It was not possible to achieve adequate fruit size when applications were very low, as at $18 \%$ to $25 \%$ ET in Irr4. Crop load reduction around mid-June had no negative consequences for fruit quality, enhancing fruit color, and soluble solids concentration (SSC) and did not affect the incidence of sumburn, internal breakdown or bitter pit at harvest.
\end{abstract}

Water restrictions in irrigated agriculture are becoming more likely in western North America (Barnett et al., 2004) including British Columbia (Whitfield and Cannon, 2000) as a consequence of climate-related factors that have included reductions in mountain snow accumulation (Mote et al., 2005), earlier snow melt and stream runoff, reduced late-season stream flow and an associated requirement for increased water withdrawal from storage reservoirs. The problem is particularly acute in the semiarid Okanagan region of southern British Columbia, which is an important Canadian production region for high-value tree fruits and wine grapes. In this region, tree fruit and wine grape production must compete for water with instream ecological requirements and a rapidly growing urban population where fresh water availability is among the lowest per person in Canada (Neilsen et al., 2006).

Interest is therefore strong in the region to consider adoption of a range of irrigation practices, which might reduce water applications while minimizing detrimental effects on fruit production. Deficit irrigation strategies, using less than optimum water applications (Behboudian and Mills, 1997; Leib et al., 2006) to maintain or even improve fruit quality (Ebel et al., 1993; Mpelasoka et al., 2000), have attracted considerable attention. Further adaptive strategies may need to be considered when a lack of water necessitates extremely low irrigation applications (Proebsting and Middleton, 1980). One such strategy for perennial fruit crops is the reduction of crop load to maintain marketable fruit size, despite reduced water applications (Girona et al., 2004; Marsal et al., 2008; Naor et al., 2008). Its successful use has been based on the major effect high crop load has on $\mathrm{C}$ partitioning and tree water relations (Palmer et al., 1997; Wünsche and Ferguson, 2005). Many of these studies have been conducted over a single year (Neilsen et al., 2010) with limited assessment of effects on fruit quality characteristics other than fruit size (Mpelasoka et al., 2001). Also, there has been limited assessment of its potential for use over a range of soil types including coarse-textured soils, which have limited water-holding capacity and comprise two-thirds of the orchard production area in southern British Columbia (Neilsen et al., 2014).

A multiyear experiment was designed to assess the effect of low, medium, and high crop load in an apple orchard grown on a typical coarse-textured soil across a range of irrigation treatments including several with reduced water application. Emphasis was placed on determining changes in soil moisture, tree water relations, yield, and fruit quality, particularly maintenance of acceptable fruit size.

\section{Materials and Methods}

'Ambrosia' apple trees (Malus $\times$ domestica) on M.9 rootstock were planted in 2003 at a $0.9 \mathrm{~m}$ (within row) $\times 3.5 \mathrm{~m}$ (between row) spacing at the Pacific Agri-Food Research Center in Summerland, BC, Canada and trained and pruned as a slender spindle system. The trees were established and maintained for the first four growing seasons under a fully automated drip irrigation system comprising two parallel irrigation lines, located $0.3 \mathrm{~m}$ either side of the tree row and each containing one $4 \mathrm{~L} \cdot \mathrm{h}^{-1}$ pressure-compensating emitter per tree. Irrigation was applied daily to replace previous day ET demand estimated by an atmometer (measures evaporation) (Parchomchuk et al., 1996) modified by a seasonal crop coefficient curve derived from Allen et al. (1998) and adjusted for the area of the orchard watered (i.e., herbicide strip). Throughout the study, the block received optimum fertigated nutrients based on cumulative research (Neilsen et al., 1999) and commercial recommendations in the region. Annual applications included fertigation of $\mathrm{N}$ daily as calcium nitrate $(15.5 \mathrm{~N}-$ $0 \mathrm{P}-0 \mathrm{~K}$ ) for 6 weeks after bloom to provide $75 \mathrm{~g} \mathrm{~N} /$ tree/year. This was a high rate of $\mathrm{N}$ fertigation as further research indicated that 
$\mathrm{N}$ application rates as low as $25 \mathrm{~g} \mathrm{~N} /$ tree can be sufficient for high-density apple trees (Neilsen et al., 2009). Phosphorus was fertigated the day after full bloom and before the start of $\mathrm{N}$ applications as ammonium polyphosphate $(10 \mathrm{~N}-15 \mathrm{P}-0 \mathrm{~K})$ and supplied $20 \mathrm{~g}$ $\mathrm{P} /$ tree/year and $13.5 \mathrm{~g} \mathrm{~N} /$ tree/year. Potassium was fertigated daily for the last 4 weeks of the $\mathrm{N}$ fertigation period as potassium chloride $(10 \mathrm{~N}-0 \mathrm{P}-50 \mathrm{~K})$ to supply $20 \mathrm{~g} \mathrm{~K} /$ tree/year. Boron (B) was fertigated as Solubor $(20 \% \mathrm{~B})$ daily from 1 to 4 weeks after full bloom to supply $0.16 \mathrm{~g} \mathrm{~B} /$ tree annually.

During the 2007-09 growing seasons, a split-plot experiment in a randomized complete block design was established with four irrigation treatments assigned to main plot units and three crop load treatments assigned to subplot units. Each subplot unit included five trees (three measurement and two guard trees). There were six replicate rows and a guard row on all four sides of the experimental block. The irrigation treatments included Irr1) continuation of the previously described irrigation regime at $100 \%$ ET replacement applied daily through the $2 \times 4 \mathrm{~L} \cdot \mathrm{h}^{-1}$ emitters per tree, Irr2) $50 \%$ ET replacement applied as in Irr1, Irr3) 50\% ET replacement applied as in Irr2 but through only one emitter per tree, and Irr4) 50\% ET replacement applied as in Irr2 except every $2 \mathrm{~d}$. Irrigation treatments were maintained over the 3 -year experimental period with the exception of Irr4, which became increasingly stressful over time with irrigation quantities reduced to $25 \%$ ET replacement in 2008 and $18 \%$ ET replacement in 2009. Irrigation treatments were applied throughout the growing season.

Crop load levels were imposed on the three-tree subplot units within each irrigation treatment whole plot by hand thinning completed by day of year (DOY) 160, 169, and 167, in 2007, 2008 and 2009, respectively, $\approx 4-5$ weeks after full bloom. Full bloom was 12 May 2007 (DOY 132), 16 May 2008 (DOY 137), and 20 May 2009 (DOY 140). The timing of hand thinning was chosen to represent a response to watering restrictions imposed by regulatory bodies in times of drought caused by limited mountain snowpack. The timing of hand thinning would be considered late for commercial growers, who thin as early as possible to improve fruit size. Crop loads were imposed at three levels including low, medium, and high with actual crop loads increasing each year as the trees grew. From 2007 to 2009, respectively, these

Received for publication 31 July 2015. Accepted for publication 30 Nov. 2015.

Financial support was provided by Agriculture and Agri-Food Canada A-base funding.

We thank the able technical assistance of Linda Herbert for gas exchange measurements, Istvan Losso for data downloading, David Gregory for TDR measurements, Bill Rabie for horticultural maintenance, and Shawn Kuchta for harvest and quality measurements and guidance for several student assistants.

${ }^{1}$ Corresponding author. E-mail: Denise.Neilsen@ agr.gc.ca. treatment targets were (low) 2.5, 3, and 3.75 fruit $/ \mathrm{cm}^{2}$ TCSA, (medium) 4.5, 6, and 7.5 fruit/ $\mathrm{cm}^{2}$ TCSA, and (high) 9, 12, and $15 \mathrm{fruit} / \mathrm{cm}^{2}$ TCSA. Crop load treatments were applied to the same trees each year with high and low crop loads alternating annually in an attempt to adjust for the tendency for biennial bearing on trees with extreme crop loads. The carryover effects of this strategy were unknown, but it was seen as a method to avoid the difficulties of maintaining three successive years of high crop load treatments on the same trees.

The experimental block was planted on a level to slightly south east facing slope on a Skaha loamy sand soil, an Aridic Haploxerall (Wittneben, 1986). These soils are common throughout the south Okanagan Valley and are often planted to tree fruits and grapes. The soils have low organic matter content $(<2 \%)$, low native fertility, drain rapidly, and generally have low waterholding capacity. Soil moisture retention curves determined on four undisturbed surface samples collected from the experimental block before planting indicated average volumetric moisture contents of $34.4 \%$ at saturation $(-0.001 \mathrm{kPa}), 19.5 \%$ at $-10 \mathrm{kPa}, 12.5 \%$ at $-33 \mathrm{kPa}, 9.1 \%$ at $-100 \mathrm{kPa}$, and $5.4 \%$ at 'permanent' wilting point $(-1500 \mathrm{kPa})$. Daily and long-term temperature and precipitation records were available from the Summerland CS weather station located at PARC, Summerland, and maintained by Environment Canada.

Volumetric soil moisture content was measured using depth-integrated $(0-40 \mathrm{~cm})$ time-domain reflectometry (TDR) (Topp and Reynolds, 1998; Tektronix, Beaverton, OR). Readings were made hourly and averaged daily during each growing season, commencing mid-June until the end of September, for three replicates of each irrigation treatment. Probes were located half way between the tree row and drip emitters. Wet- and dry-side measurements were made for treatment Irr3. No provision was made for monitoring differences in soil moisture content among crop load treatments as the same trees within each irrigation treatment were monitored throughout the study. Periodic leaf photosynthesis and $g_{\mathrm{S}}$ measurements were made during each growing season (on 11, 8, and 6 occasions, 2007 to 2009, respectively). Measurements were made on high and low crop load plots in four replicates of three irrigation treatments (Irr1, Irr2, Irr3) in 2007 and on three replicates of all irrigation treatments (Irr1 to Irr4) in 2008 and 2009. Measurements were made for

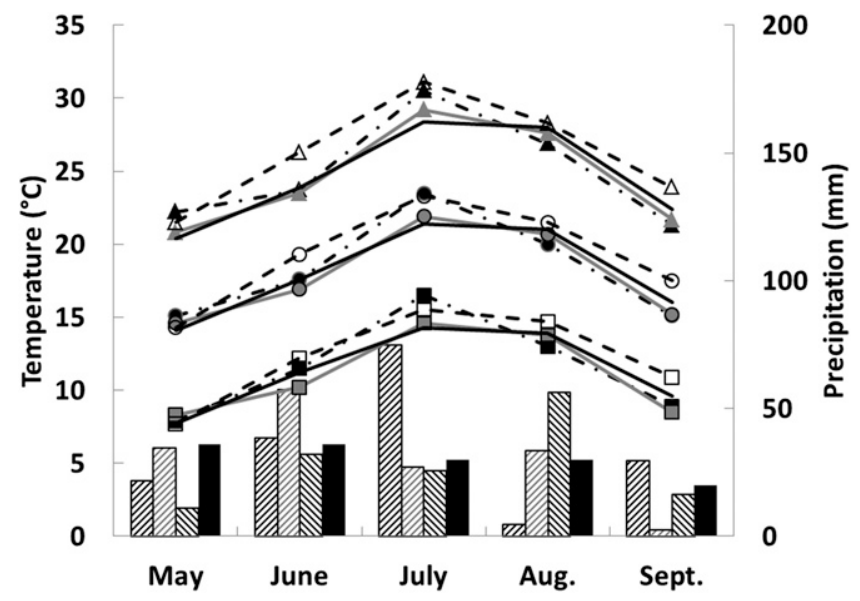

Fig. 1. Monthly average minimum $(\square)$, mean $(\bigcirc)$, and maximum $(\triangle)$ daily temperature for $2007(--)$ 2008 (一); 2009 (--); 1981-2010 averages (-) and total monthly precipitation for 2007 (ख)); 2008 (ख);

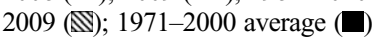

Table 1. Actual water applications for different irrigation treatments, 2007-09, expressed on a per tree and unit area basis with comparison of drip relative to sprinkler irrigation.

\begin{tabular}{rcccc}
\hline Irrigation (\% ET) & $\begin{array}{c}\text { Water application } \\
(\mathrm{L} / \text { tree })\end{array}$ & $\begin{array}{c}\text { Water application } \\
\left({\left.\mathrm{L} \cdot h a^{-1}\right)}^{-}\right.\end{array}$ & $\begin{array}{c}\text { Drip irrigation } \\
\left(\mathrm{mm} \cdot \mathrm{ha}^{-1}\right)\end{array}$ & $\begin{array}{c}\text { Sprinkler irrigation } \\
\left(\mathrm{mm} \cdot \mathrm{ha}^{-1}\right)\end{array}$ \\
\hline 100 & & 2007 & & \\
50 & 1,463 & $4.88 \times 10^{6}$ & 488 & 784 \\
& 721 & $2.40 \times 10^{6}$ & 240 & 386 \\
\hline 100 & & 2008 & & 580 \\
50 & 1,149 & $3.83 \times 10^{6}$ & 383 & 288 \\
25 & 570 & $1.90 \times 10^{6}$ & 190 & 141 \\
& 280 & $0.93 \times 10^{6}$ & 93 & \\
\hline 100 & & 2009 & & 660 \\
50 & 1,305 & $4.31 \times 10^{6}$ & 421 & 119 \\
18 & 586 & $1.94 \times 10^{6}$ & 194 & 78 \\
\hline
\end{tabular}


each treatment and replicate on three, young, fully expanded leaves exposed to full sun using an open gas exchange system (LI-COR 6400; LI-COR Inc., Lincoln, NE), typically between 1100 and $1400 \mathrm{HR}$. Where possible, the 1- to 1.5-h time frame for completion of the 72 measurements was centered on solar noon, but was sometimes shifted within the 1100- to 1400 -HR period to avoid cloud cover. Midday stem water potential measurements were made, where possible, on the same day as gas exchange measurements, and on the same treatments also throughout the three growing seasons, eight times in 2007 and five times in 2008 and 2009. Each time, midday stem water potential was determined on three leaves per treatment after shielding the leaf with black plastic and aluminum foil for $2-3 \mathrm{~h}$ before measurement of water potential using a pressure chamber (McCutchan and Shackel, 1992).

Trunk diameter at $0.3 \mathrm{~m}$ above the graft union was measured annually during dormancy (November to January) and used to calculate TCSA and these values were used to adjust crop load treatments (number of fruits/TCSA) for the upcoming season. Each year for each treatment tree, the total number of fruit were counted and weighed from a single picking at commercial harvest on 25 Sept. 2007, 30 Sept. 2008, and 5 Oct. 2009. Average fruit weight per tree was calculated from harvest fruit counts and total weight. A 25-apple sample was randomly selected from the three tree boxes and pooled for each experimental plot. Fruit were evaluated annually for flesh firmness, skin color, titratable acidity (TA), and SSC. Flesh firmness was determined with a Baullaf penetrometer (Lake City Technical Products Ltd., Kelowna, BC, Canada) with an 11.1-mmdiameter tip. Percent red skin color was estimated visually. SSC of the juice was measured with a refractometer and TA was determined by titration of juice with $0.1 \mathrm{M} \mathrm{NaOH}$ to an 8.1 $\mathrm{pH}$ end point with data expressed as $\mathrm{g} / 100 \mathrm{~mL}$ malic acid equivalents. An additional random subsample of 10 fruit at harvest was used to calculate incidence of disorders including water core, sunburn, internal breakdown, and bitter pit.

Analysis of variance was performed on all measured soil and plant variables using the GLM procedure (SAS, 2006). The experimental design was a split plot with four irrigation main plot treatments, three crop load subplots, and six replicates. TDR soil moisture readings were made only on the four irrigation treatments in the $\mathrm{C} 2$ plots and were analyzed as a randomized block design with three replicates. Leaf photosynthesis, $g_{\mathrm{S}}$, and midday stem potential measurements were made on three irrigation treatments with four reps in 2007 and three reps in 2008-09 and restricted to the low and high crop load treatments. An arcsin transformation was performed on percent data (red color) before analysis. Data were analyzed separately by year due to changes in crop load treatments over time as trees grew larger in addition to the practical necessity of alternating high and low crop loads annually. All plot trees were included in a regression analysis to determine crop load thresholds for an acceptable average fruit size $(200 \mathrm{~g})$ under different irrigation treatments.

\section{Results and Discussion}

Weather. In general, weather patterns suggest the study period was representative of typical conditions for this semiarid fruit growing region during May to September (normal irrigation season), although average monthly temperatures exceeded long-term averages the 3 years the experiment was maintained. Exceptions were Aug. 2007 and May 2008 when averages were less than long-term normals (Fig. 1). Cumulative
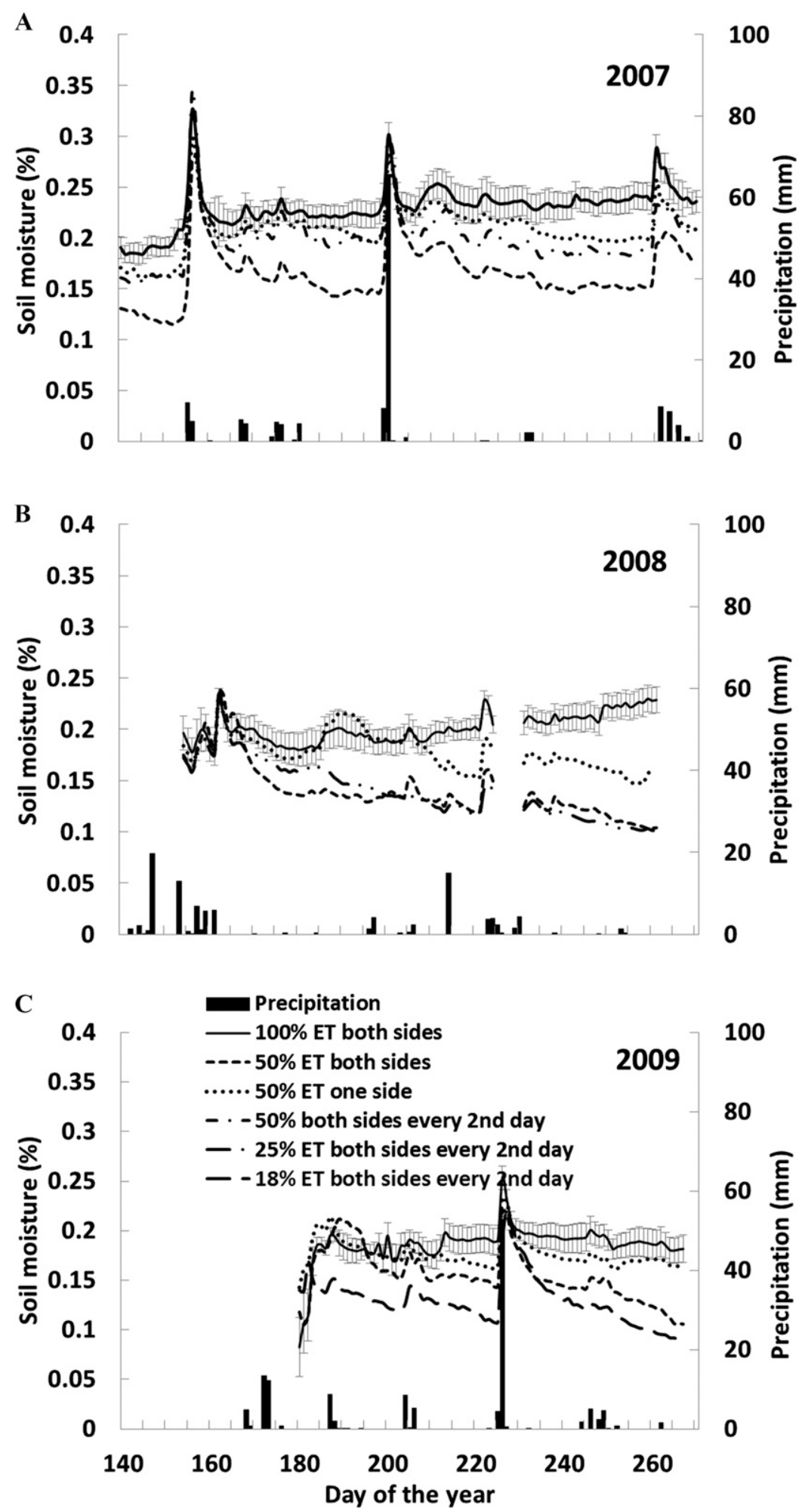

Fig. 2. Average daily volumetric soil moisture content, measured hourly for each irrigation treatment and daily precipitation during the main growing season (day of year 140-270) during (A) 2007, (B) 2008, and (C) 2009. Vertical bars $=+1 \mathrm{sE}$ indicated on the $100 \%$ evapotranspiration replacement treatment. 
precipitation from May to September was below normal in the last 2 years of the study and above normal in the first year. However, cumulative totals did not fluctuate more than $11 \%$ from long-term normals $(152 \mathrm{~mm})$ during these 5 months. Individual months when precipitation was more than double long-term averages included July 2007 and June 2008, which were each followed by relatively dry months when precipitation was less than normal values (Aug. 2007, July 2008). Similar dry months occurred in Sept. 2008 and May 2009 (Fig. 1).

Climate change scenarios for the Okanagan basin, where this study was undertaken, have indicated that existing water supply may be unable to cope with the increased demand associated with projected increases in peak ET requirements and length of the growing season (Neilsen et al., 2006). This has increased interest in irrigation strategies that reduce water applications without compromising fruit production. In our study, annual water reductions, ranging from $18 \%$ to $50 \%$ of maximum, were imposed over a 3-year period and have been expressed as volumes per tree or unit area of land (Table 1). It is also apparent from these calculations that substantial water savings resulted from the use of drip rather than overlapping sprinkler irrigation that would have wet the whole orchard floor. Annual water applications by drip ranged from $62 \%$ to $66 \%$ of what would have been applied for the same treatments if sprinkler irrigation had been used.

Soil moisture. Irrigation treatments affected volumetric moisture content in the surface $40 \mathrm{~cm}$ of the soil throughout the study from 2007-09 (Fig. 2). The highest average profile moisture content was measured for Irr1, which received irrigation at $100 \%$ ET replacement (both sides) with daily moisture values fluctuating around and frequently exceeding $20 \%$ by volume, the $10 \mathrm{kPa}$ presumed field capacity value for this soil. Intermediate soil moisture values were measured for the "wet" side of Irr3, which received per tree irrigation averaging $50 \%$ of ET replacement but applied through one emitter on one side of the tree. The moisture content of this treatment frequently exceeded that of Irr2, which received the same amount of water split between two emitters. Driest soil moisture values were observed for the dry side of Irr3 (data not shown) and Irr4, which received minimal water applications per tree that became progressively more severe from 2007 to 2009. In 2009, when Irr4 applications were made at $18 \%$ ET replacement, moisture contents declined below $10 \%$. It is also notable that early season moisture values in 2009 were very low for all irrigation treatments when TDR measurements commenced following a very dry May (Figs. 1 and 2C). Intermediate to low soil moisture values were observed for soils receiving irrigation at $50 \%$ of ET through both emitters. During the study, soil moisture values increased for all irrigation treatments including around DOY 200 and 260 in 2007 (Fig. 2A), DOY 222 in 2008 (Fig. 2B), and DOY 225 in 2009 (Fig. 2C) coinciding with periods of natural precipitation. In 2007 and 2009, rainfall events of $50 \mathrm{~mm}$ masked differences in irrigation treatments for $\approx 1$ week. There was also a period of equipment malfunction, DOY 225 to 230 in 2008 (Fig. 2B).

The differences in soil moisture were measured in an important portion of the root zone as apples grown on M.9 rootstock, receiving daily irrigation and fertigation, have previously been shown to have an average rooting depth of less than $0.3 \mathrm{~m}$ in a similar loamy sand soil (Neilsen et al., 1997). It was noteworthy that minimum measured soil moisture contents of $\approx 10 \%$ by volume in irrigation treatment Irr4 in the final year of the study occurred at moisture retention values of $\approx-100 \mathrm{kPa}$.

Yield and fruit size. Targeted and significantly different low, medium, and high crop loads were achieved annually, 2007-09, when harvested, counted, weighed, and expressed as number of fruit $/ \mathrm{cm}^{2}$ of dormant season TCSA (Table 2). Irrigation treatments did not affect crop load in any year. Tree yield paralleled crop load treatments in the first year of the study (2007), increasing as crop load increased from low to high. There were no yield differences among irrigation treatments in 2007. However, in 2008 and 2009 , there was a significant interaction between crop load and irrigation treatments, with yield unaffected by irrigation treatment at the low crop load in 2008, but with significant differences among irrigation treatments at medium and high crop loads in 2008 and among all crop loads in 2009. In these 2 years highest overall yield was associated with Irr1 (100\% ET replacement irrigation) and lowest yields for trees receiving only $25 \%$ and $18 \%$ ET replacement irrigation, respectively.

Fruit size (fresh weight) consistently declined as crop load increased exhibiting a larger range of values than those associated with irrigation treatments (Table 2). Irrigation treatments also affected fruit size each year with largest fruit observed for Irr1, although not significantly different from Irr2 and Irr3 fruit in 2008. Smallest fruit was observed in the Irr4 treatment although size was not significantly smaller than Irr2 fruit and Irr3 fruit in 2007, the first year of the study. Very small fruit $(<100 \mathrm{~g})$ were observed in 2009 for the high crop load and the greatest irrigation deficit when Irr4 trees received irrigation at $18 \%$ ET replacement.

Crop load has long been recognized as having a major effect on annual apple yield and fruit size (Hansen, 1973; Palmer et al., 1997; Volz et al., 1993) and over multiple, successive growing seasons (Yuri et al., 2011), with high crop load reducing fruit size over a range of apple cultivars (Wünsche and Ferguson, 2005) due to competition for photoassimilates. An interaction between tree water status and crop load has been shown for many fruit tree cultivars, including peach (Girona et al., 2004), pear (Marsal et al., 2008), and apple (Naor et al., 2008), so that

Table 2. Actual measured crop load, yield, and fruit size as affected by crop load and irrigation treatment, $2007-09$.

\begin{tabular}{|c|c|c|c|c|c|c|c|c|c|c|c|c|c|}
\hline \multirow[b]{2}{*}{ Crop load ${ }^{z}(\mathrm{C})$} & \multicolumn{3}{|c|}{ Measured crop load (N/cm ${ }^{2}$ TCSA) } & \multicolumn{7}{|c|}{ Yield (kg/tree) } & \multicolumn{3}{|c|}{ Fruit size (g) } \\
\hline & 2007 & 2008 & 2009 & 2007 & & 2008 & & & 2009 & & 2007 & 2008 & 2009 \\
\hline Low & $2.7 \mathrm{c}$ & $3.6 \mathrm{c}$ & $3.6 \mathrm{c}$ & $7.2 \mathrm{c}$ & & & & & & & $264 \mathrm{a}$ & $244 \mathrm{a}$ & $233 \mathrm{a}$ \\
\hline Medium & $4.9 \mathrm{~b}$ & $6.4 \mathrm{~b}$ & $7.5 \mathrm{~b}$ & $12.1 \mathrm{~b}$ & & & & & & & $246 \mathrm{~b}$ & $199 \mathrm{~b}$ & $159 \mathrm{~b}$ \\
\hline High & $8.7 \mathrm{a}$ & $10.5 \mathrm{a}$ & $15.3 \mathrm{a}$ & $15.5 \mathrm{a}$ & & & & & & & $182 \mathrm{c}$ & $139 \mathrm{c}$ & $96 \mathrm{c}$ \\
\hline Significance & $* * * *$ & $* * * *$ & $* * * *$ & $* * * *$ & & & & & & & $* * * *$ & $* * * *$ & $* * * *$ \\
\hline Irrigation (I) & & & & & Low & Medium & High & Low & Medium & High & & & \\
\hline Irr1 & 5.2 & 6.8 & 9.1 & 11.6 & 9.7 & 17.2 & 21.9 & 13.1 & 20.9 & 22.5 & $250 \mathrm{a}$ & $216 \mathrm{a}$ & $187 \mathrm{a}$ \\
\hline Irr2 & 5.5 & 6.7 & 9.6 & 11.0 & 9.1 & 14.5 & 18.1 & 12.9 & 15.7 & 19.9 & $230 \mathrm{~b}$ & $193 \mathrm{a}$ & $159 \mathrm{~b}$ \\
\hline Irr3 & 5.7 & 6.7 & 10.1 & 11.4 & 8.8 & 15.8 & 18.3 & 9.7 & 22.5 & 15.7 & $223 \mathrm{~b}$ & $211 \mathrm{a}$ & $152 \mathrm{~b}$ \\
\hline $\operatorname{Irr} 4^{y}$ & 5.4 & 7.0 & 10.4 & 11.2 & 8.1 & 10.7 & 12.2 & 9.4 & 10.2 & 12.9 & $228 \mathrm{~b}$ & $157 \mathrm{~b}$ & $98 \mathrm{c}$ \\
\hline Significance & NS & NS & NS & NS & & & & & & & $* * * *$ & $* * *$ & $* * * *$ \\
\hline $\mathrm{C} \times \mathrm{I}$ interaction & NS & NS & NS & NS & & $*$ & & & $*$ & & NS & NS & NS \\
\hline SE of interaction mean & & & & & & 1.0 & & & 1.5 & & & & \\
\hline
\end{tabular}

Irr1: 100\% evapotranspiration (ET) both sides daily; Irr2: 50\% ET both sides daily; Irr3: 50\% ET one side daily; Irr4: every two days, both sides at 50\% ET (2007), $25 \%$ ET (2008), and 18\% ET (2009).

NS, $* * * *, * * * *$ Nonsignificant or means significantly different at $P=0.05,0.001$, or 0.0001 , respectively.

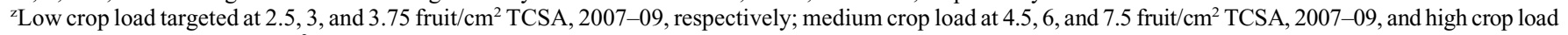
target at 9,12 , and 15 fruit $/ \mathrm{cm}^{2}$ TCSA, 2007-09.

${ }^{\mathrm{y}}$ Irrigation for this treatment reduced to 25\% ET (2008) and 18\% ET (2009). 
judicious fruit thinning can be applied to minimize fruit size reduction on water stressed trees. In our multiple year study on 'Ambrosia' apple on M.9 rootstock, a 3- (first 2 years) to 4-fold (last year) range of crop load treatments were maintained across contrasting season-long drip irrigation treatments including presumed minimum stress $(100 \%$ ET) and several deficit treatments as low as $18 \%$ ET in the 3rd year. Over the 3 years of the project, actual crop loads for measurement trees ranged between 2.0 and 20.7 fruit $/ \mathrm{cm}^{2}$ TCSA.

Plant water status. Midday stem water potential fluctuated within the -0.9 to -2.8 MPa range observed by Naor et al. (2008) who considered values around and below $-2.0 \mathrm{MPa}$ to be indicative of detrimental water stress. In this study, volumetric soil moisture content below $15 \%$ resulted in average seasonal declines in midday stem water potential (Fig. 3) to $-1.8 \mathrm{MPa}$ with some individual readings as low as $-2.4 \mathrm{MPa}$. Significant plant stress was observed at soil moisture contents between $15 \%$ and $10 \%$, equivalent to soil moisture potentials of -20 to $-100 \mathrm{kPa}$, particularly under high evaporative demand supporting Hillel's contention (2004) that the wilting point and plant water stress depend on evaporative demand relative to hydraulic conductivity rather than soil water potential per se. For apple, with its sparse rooting system, this is likely the result of localized drying, which can reduce soil hydraulic conductivity and water supply (Naor, 2006). This may be exacerbated by high plant hydraulic resistance which will also contribute to low plant water potential during times of high evaporative demand (Landsberg and Jones, 1981).

Crop load effects were apparent within days of imposition of crop load treatments in 2007 (Fig. 4A) and at first measurement in 2008 and 2009 (Fig. 4B and C). Differences between crop load treatments were observed throughout the growing season in all years with minimum midday stem water potential values observed later in the growing season (Fig. 4). There were no effects of irrigation treatments on midday stem water potentials in the first year (Fig. 4D). After the first year, stem water potential generally reflected the amount of water applied with $100 \%$ ET replacement treatments supporting least negative potentials, commonly in the -1.0 to $-1.2 \mathrm{MPa}$ range (Fig. $4 \mathrm{E}$ and $\mathrm{F}$ ). Trees receiving $50 \%$ ET replacement irrigation had intermediate values regardless of whether water was applied to one or both sides of the tree whereas Irr4, with minimum water applications ( $18 \%$ to $25 \%$ ET replacement), had midday stem potential values declining to values approaching and below $-2.0 \mathrm{MPa}$ late in the growing season (Fig. 4E and F). Even with presumed optimum irrigation ( $100 \%$ ET replacement, Irr1), midday stem water potential often ranged between -1.0 and $-1.3 \mathrm{MPa}$, a further indication of the difficulty of maintaining unstressed conditions in coarse-textured soils, despite applying irrigation daily.
Leaf photosynthesis and $g_{\mathrm{S}}$. Gas exchange variables were less sensitive and consistent indicators of plant stress in response to crop load and irrigation deficits than midday stem potential. In general, crop load treatments had less effect than irrigation treatments on net leaf photosynthesis and $g_{\mathrm{S}}$, with minimal interaction between treatments. Compared with low crop load trees, high crop load tree had greater net leaf photosynthesis and $g_{\mathrm{S}}$ after DOY 200 in 2007, before DOY 200 in
2008 and did not differ in 2009 (data not shown).

Increased leaf photosynthesis has been widely reported for fruiting relative to nonfruiting trees (Wünsche and Ferguson, 2005). However, little increase in photosynthetic rate was observed for trees with greater than 12 fruit $/ \mathrm{m}^{2}$ leaf area (Palmer et al., 1997), which translated into $\approx 4.5$ fruit $/ \mathrm{cm}^{2}$ TCSA estimated from their reported fruit number and TCSA values. Increased photosynthetic

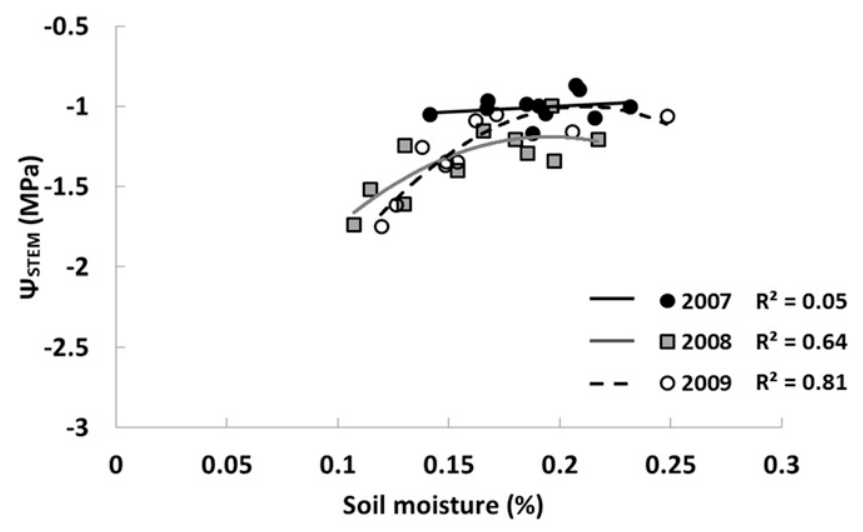

Fig. 3. Relationship between seasonal average midday stem water potential $\left(\Psi_{\text {Стем }}\right)$ and seasonal average volumetric soil moisture content in 2007, 2008, and 2009. $\mathrm{N}=11$ for each year.

A
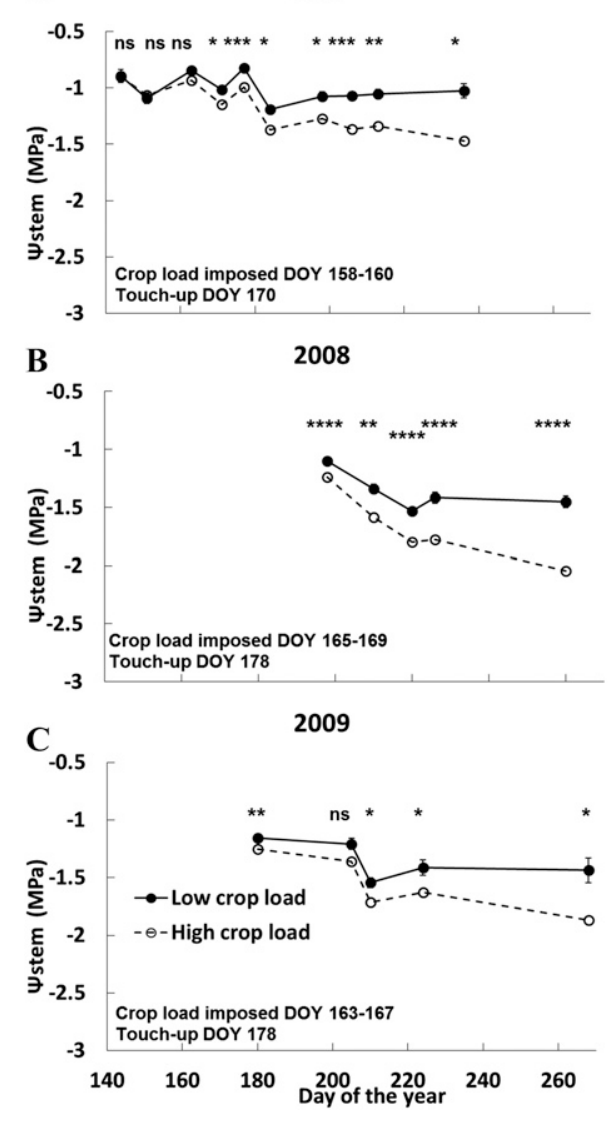

Fig. 4. Midday stem water potential $\left(\Psi_{\text {Стем }}\right)$ as affected by low and high crop load in (A) 2007, (B) 2008 , (C) 2009 and by irrigation treatments in (D) 2007, (E) 2008, (F) 2009 growing seasons. Vertical error bars $= \pm 1 \mathrm{SE}$. Differences between treatment means: * $(p \leq 0.05) ; * *(p \leq 0.01) ; * * *(p \leq 0.001)$; $* * * *(p \leq 0.0001)$. 
activity was occasionally observed as crop load increased $\approx 4$-fold from 2.5 to 9 fruit/ $\mathrm{cm}^{2}$ TCSA or from 3.75 to 12 fruit $/ \mathrm{cm}^{2}$ TCSA in first and second year, respectively. This effect had disappeared by the 3 rd year when the low crop load, 3.75 fruit $/ \mathrm{cm}^{2}$ TCSA, was close to the 4.5 fruit $/ \mathrm{cm}^{2}$ upper limit of crop load influence on photosynthesis (Palmer et al., 1997).

As the severity of deficits increased from 2007 to 2009 , net leaf photosynthesis and $g_{S}$ were increasingly affected by the irrigation treatments (data not shown). Effects were minimal in 2007. Increasing the deficit in Irr $4 \%$ to $25 \%$ ET replacement in 2008 and $18 \%$ ET replacement in 2009, reduced net leaf photosynthesis and $g_{\mathrm{S}}$ toward the end of the growing season in 2008 and throughout the growing season in 2009 compared with Irr1 (100\% ET replacement). These results mirrored differences in soil moisture contents (Fig. 2) and were consistent with declines in leaf gas exchange associated with deficit irrigation for apple (Ebel et al., 1993; Mills et al., 1996) and pear (Marsal et al., 2008).

To understand better the effects of crop load management and irrigation deficits on plant performance, seasonal averages of gas exchange and plant water status variables were plotted for all years (Fig. 5 and 6). $g_{S}$ was strongly correlated to leaf photosynthetic rate (Fig. 5A) regardless of crop load treatment. Consistent with findings of Lakso (2014) that apple stomata avoid excessive opening resulting in high water use efficiency, irrigation deficits of $50 \%$ did not change the coupling of $g_{\mathrm{S}}$ and photosynthesis (Fig. 5B). However, the relationship weakened when irrigation applications were reduced to $18 \%$ to $25 \%$ ET irrigation (Irr4) in 2008 and 2009 as indicated by the difference in slope of the regression lines for these treatments. This can be explained by the reduction in $g_{S}$ in response to declining midday stem water potentials (Fig. 6). At higher crop loads, $g_{S}$ was higher at a given stem water potential suggesting that sensitivity of $g_{\mathrm{S}}$ to water stress was less than at lower crop loads as suggested for pear by Marsal et al. (2008), apple and olive (Naor, 2014). Consequently, it was at the greatest irrigation deficits (18\% to $25 \%$ ET replacement), that the strongest relationship existed between actual crop load (for each measurement tree) and stem water potential (Fig. 7).

To examine further the factors controlling fruit size at different crop loads, plots were recategorized into those with $<6,6-12$, and $>12$ fruit $/ \mathrm{cm}^{2}$ TCSA. Fruit size at harvest was linearly related to stem water potential (Fig. 8), but not to $g_{\mathrm{S}}$ and net photosynthesis (data not shown). Fruit size deceased as crop load increased and midday stem water potential decreased. Despite the higher rates of $g_{S}$ at a given stem water potential for higher crop loads (Fig. 7) fruit size declined rapidly below a target economic size of $200 \mathrm{~g}$ at crop loads greater than 6 fruit $/ \mathrm{cm}^{2}$ TCSA, in response to low stem potentials (Fig. 8). This suggests an upper limit to crop load imposed by competition for photoassimilates, which
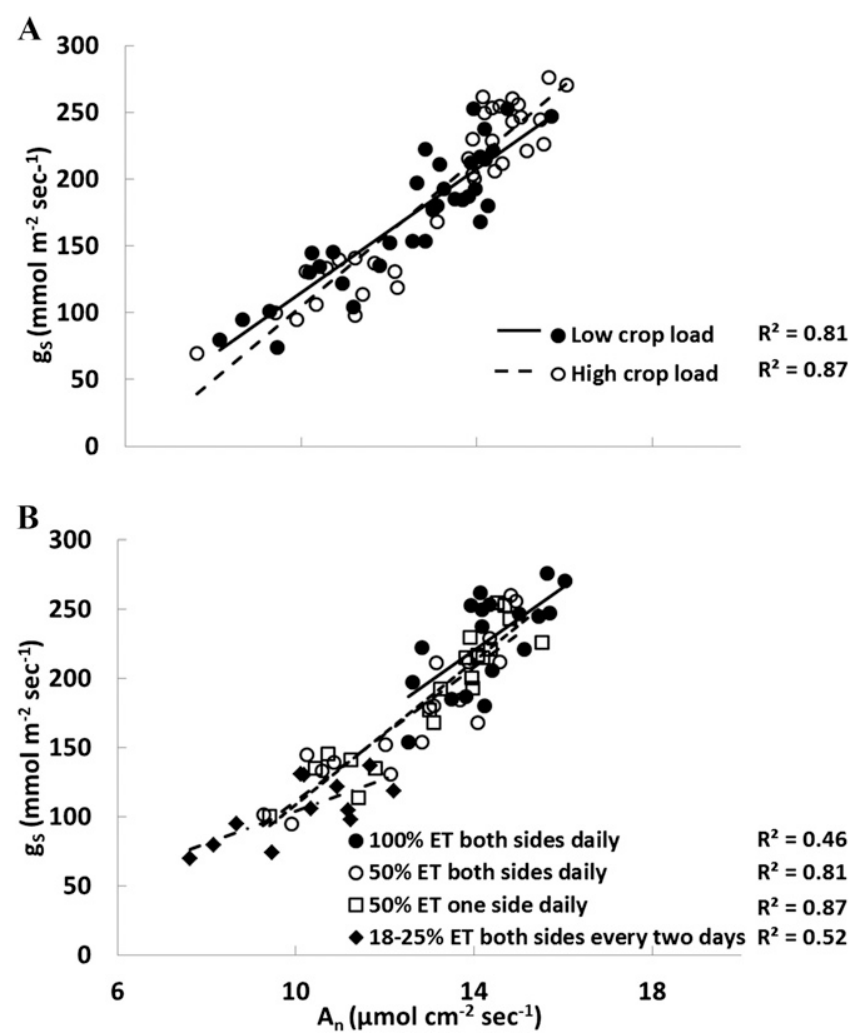

Fig. 5. Relationships between annual average stomatal conductance $\left(g_{\mathrm{S}}\right)$ and net photosynthesis $\left(\mathrm{A}_{\mathrm{n}}\right)$ in response to $(\mathbf{A})$ crop load $(n=34)$ and $(\mathbf{B})$ irrigation treatment $(n=18$, except for the $18-25 \%$ evapotranspiration every second day treatment where $\mathrm{n}=11$ ). Data for all years are included.

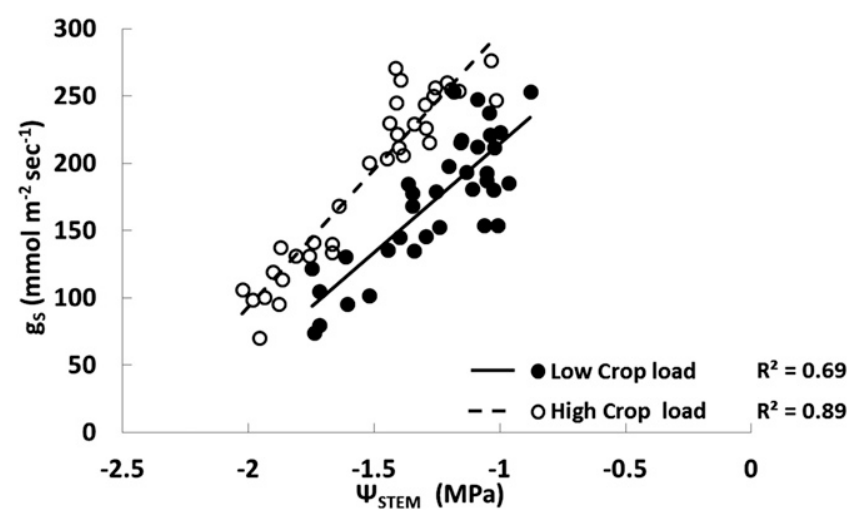

Fig. 6. Relationship between annual average stomatal conductance $\left(g_{\mathrm{S}}\right)$ and midday stem water potential $\left(\Psi_{\text {stem }}\right)$ as affected by crop load. Data for each measurement plot in all years are included, $\mathrm{n}=34$.

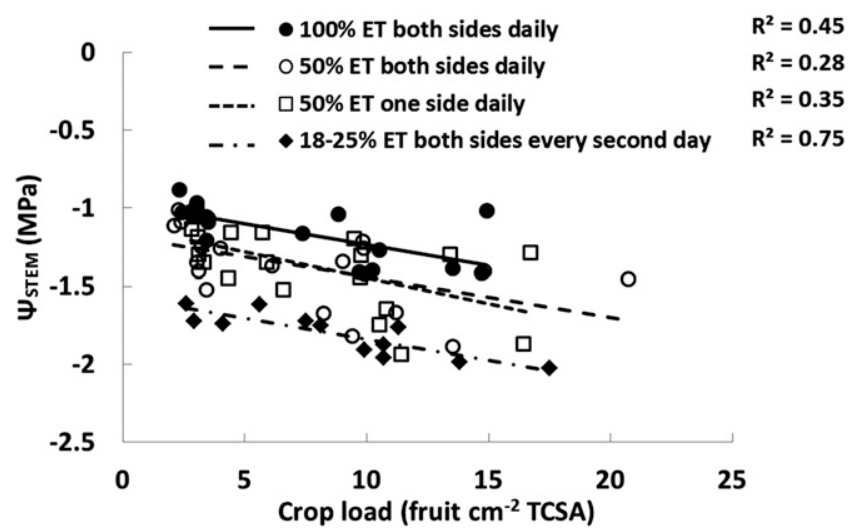

Fig. 7. Relationships between midday stem water potential $\left(\Psi_{\text {STEM }}\right)$ and crop load as affected by irrigation treatments $(n=18$, except for the $18-25 \%$ evapotranspiration every second day treatment where $\mathrm{n}=11)$. Data for all years are included. 


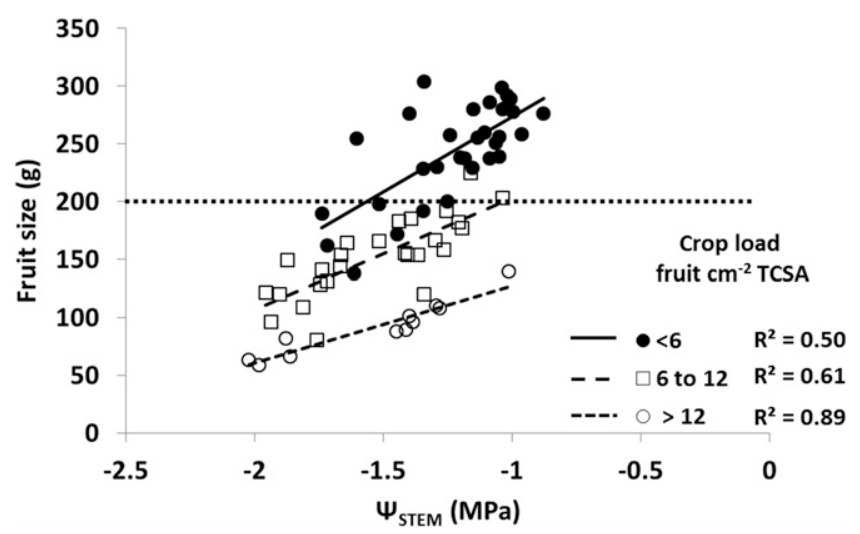

Fig. 8. Relationships between fruit size and midday stem water potential $\left(\Psi_{\text {Sтем }}\right)$ as affected by actual crop load $\left[<6\right.$ fruit $/ \mathrm{cm}^{2}$ trunk cross-sectional area (TCSA) $\mathrm{n}=32 ; 6-12$ fruit $/ \mathrm{cm}^{2}$ TCSA $\mathrm{n}=26$; $>12$ fruit $/ \mathrm{cm}^{2}$ TCSA $\left.\mathrm{n}=11\right]$.

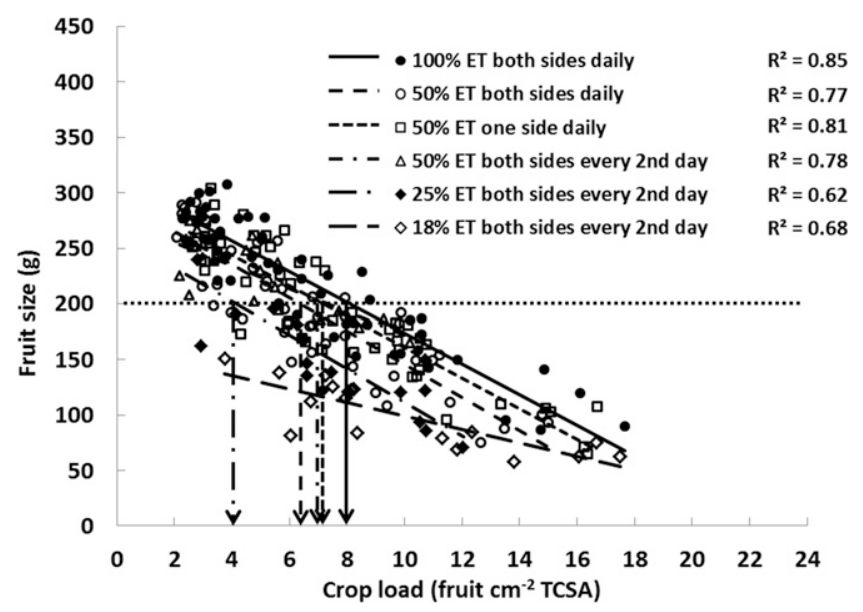

Fig. 9. Relationships between fruit size and actual crop load for all plots and for each irrigation treatment. Data for 2007, 2008, and 2009 are pooled. Vertical arrows indicate the crop load required to yield an average fruit weight of $200 \mathrm{~g}$. Data for all treatment plots are included; $\mathrm{n}=54$ for the daily irrigation treatments and $\mathrm{n}=17$ for the every second day irrigation treatments.

was reduced as tree water status declined and became an increasingly important determinant of $g_{\mathrm{S}}$ (Marsal et al., 2008; Naor et al., 2008).

The effect of crop load on fruit growth in response to tree water status associated with different deficit irrigation strategies can be used to devise potential management strategies in times of drought. In all years for all irrigation treatments, there was a highly significant linear relationship between fruit size and crop load when data from individual trees for all replicates were plotted $\left(R^{2}\right.$ ranging from 0.74 to $0.85, \mathrm{n}=54$, for daily irrigation treatments and from 0.62 to 0.78 for alternate day irrigation treatments, $\mathrm{n}=17$ ), (Fig. 9). Assuming a desired average fruit size of $200 \mathrm{~g}$, a crop load of $\approx 8$ fruit $/ \mathrm{cm}^{2}$ TCSA was achievable over the 3 years at Irr $1(100 \%$ ET irrigation). Reducing season-long irrigation to $50 \%$ ET replacement would have reduced optimum crop load slightly, to 7 fruit $/ \mathrm{cm}^{2}$ TCSA if applied, either every second day or to one side of the tree, and to $6.5 \mathrm{fruit} / \mathrm{cm}^{2}$ if applied to both sides of the tree. At $25 \%$ irrigation applied every second day, as in 2008, crop load would need to be reduced to 4 fruit $/ \mathrm{cm}^{2}$
TCSA to achieve $200 \mathrm{~g}$ fruit (Fig. 9). In 2009, with annual irrigation at $18 \%$ ET replacement, it was not possible to achieve $200 \mathrm{~g}$ fruit by reducing crop load. This year was characterized by a very dry May occurring at the time of cell division when apple is particularly sensitive to water stress (Wünsche and Ferguson, 2005). The irrigation treatments imposed in our study were season long. The fruit size data from 2009 suggest that delaying the imposition of deficit irrigation until after cell division (4-5 weeks post bloom) would be a good practical strategy, particularly since water savings by deficit irrigation at a time of relatively low ET are not large.

In general, these results support, for 'Ambrosia' apple, the contention that for many fruit tree crops (Girona et al., 2004; Marsal et al., 2008; Naor et al., 2008) reducing crop load can maintain fruit size under conditions of water stress, provided the reduced water applications do not compromise early apple growth during cell division or are so severe $(<50 \%$ ET replacement) that reasonable apple size cannot be achieved.

Fruit quality. Fruit quality, as measured by fruit firmness, red coloration, soluble solids, and TA was usually affected by crop load treatments with effects commencing the first year of the study in 2007, whereas irrigation effects became apparent in years 2 and 3 (2008-09) (Table 3). In 2007, increased firmness was associated with low crop load, whereas the opposite was observed in 2009. In 2008, there was a significant interaction between irrigation treatment and crop load with firmer fruit at Irr4 relative to Irr2 at the medium crop load and relative to all other irrigation treatments at the high crop load. Firmest fruit were also measured for Irr4 trees when water application was reduced to $18 \%$ ET replacement in 2009 . Percent red color was enhanced at low crop loads in 2008-09 and reduced at Irr4 in 2009. Soluble solids content was consistently highest at low crop load and at Irr4 in 2008 and 2009. Titratable acidity was consistently highest at low crop load, including in 2008 when there was a significant interaction between crop load and irrigation treatments. Titratable acidity was highest for Irr4 fruit in 2009 , but only at the high crop load in 2008. There were no quality differences observed between fruit in response to water applications on one (Irr3) or both (Irr2) sides of the tree. Few fruit disorders were observed at commercial harvest throughout the study with incidence of breakdown $(0.7 \%)$ and bitter pit $(0.05 \%)$ rare and unrelated to treatments. The most common harvest disorders were water core $(16 \%$ of fruit) and sunburn (5\%). Only water core was related to treatments, being higher at low crop loads in 2007-08 and at Irr1 in 2009 (data not shown).

Other than for fruit size (e.g., Naor et al., 2008), there have been few studies that have investigated the effects of interaction between irrigation and crop load on fruit quality. In a single-year study, Mpelasoka et al. (2001) found no interaction between crop load and irrigation. In our 3-year study, interactions were not observed for red color and soluble solids and only in a single year (2008) for firmness and TA. Crop load consistently affected fruit quality with red color and SSC increased at low crop load as has been generally observed for apple (Wünsche and Ferguson, 2005). This suggests that reducing crop load to mitigate water stress will generally be beneficial to fruit quality in addition to increasing fruit size. An exception was fruit firmness, which showed a transition from firmest fruit in first year at low crop load to firmest fruit at high crop load in the 3rd year, the latter effect a likely consequence of extremely small fruit at high crop load in 2009. Ebel et al. (1993) reported a similar relationship between very small fruit and increased fruit firmness. Three of the four irrigation treatments involved maintenance of season-long water deficits, and the elevation of fruit SSC associated with these irrigation treatments is consistent with elevated SSC frequently reported after deficit irrigation (Ebel et al., 1993; Mills et al., 1996; Mpelasoka et al., 2000). Otherwise, effects of irrigation on fruit quality were limited to reduced red color, high TA, and firmer fruit 
Table 3. Fruit quality as affected by crop load and irrigation treatments 2007-09.

\begin{tabular}{|c|c|c|c|c|c|c|c|c|c|c|c|c|c|c|c|c|}
\hline \multirow[b]{2}{*}{ Crop loadz (C) } & \multicolumn{5}{|c|}{ Firmness $(\mathrm{N})$} & \multicolumn{3}{|c|}{ Red (\% solid red) } & \multicolumn{3}{|c|}{ Soluble solids (\%) } & \multicolumn{5}{|c|}{ Titratable acidity ( $\mathrm{g} / 100 \mathrm{~mL}$ malic acid equivalent) } \\
\hline & 2007 & & 2008 & & 2009 & 2007 & 2008 & 2009 & 2007 & 2008 & 2009 & 2007 & & 2008 & & 2009 \\
\hline Low & $81.7 \mathrm{a}$ & & & & $74.4 \mathrm{~b}$ & 63 & $67 \mathrm{a}$ & $56 \mathrm{a}$ & $14.7 \mathrm{a}$ & $15.4 \mathrm{a}$ & $14.5 \mathrm{a}$ & $0.42 \mathrm{a}$ & & & & $0.55 \mathrm{a}$ \\
\hline Medium & $78.8 \mathrm{~b}$ & & & & $72.7 \mathrm{~b}$ & 67 & $62 \mathrm{~b}$ & $46 \mathrm{~b}$ & $14.1 \mathrm{~b}$ & $14.8 \mathrm{~b}$ & $13.3 \mathrm{~b}$ & $0.38 \mathrm{~b}$ & & & & $0.47 \mathrm{~b}$ \\
\hline High & $76.3 \mathrm{c}$ & & & & $78.5 \mathrm{a}$ & 58 & $40 \mathrm{c}$ & $31 \mathrm{c}$ & $13.3 \mathrm{c}$ & $14.4 \mathrm{~b}$ & $13.1 \mathrm{~b}$ & $0.31 \mathrm{c}$ & & & & $0.40 \mathrm{c}$ \\
\hline Significance & $* * * *$ & & & & $* * * *$ & NS & $* * * *$ & $*$ & $* * * *$ & $* * * *$ & $* *$ & $* * * *$ & & & & $* * * *$ \\
\hline Irrigation (I) & & Low & Medium & High & & & & & & & & & Low & Medium & High & \\
\hline Irr1 & 79.4 & 86.4 & 81.5 & 78.5 & $74.2 \mathrm{~b}$ & 58 & 62 & $48 \mathrm{a}$ & 13.8 & $13.8 \mathrm{c}$ & $13.3 \mathrm{~b}$ & 0.40 & 0.39 & 0.33 & 0.28 & $0.44 \mathrm{~b}$ \\
\hline Irr2 & 78.4 & 86.9 & 79.8 & 79.3 & $74.6 \mathrm{~b}$ & 64 & 57 & $45 \mathrm{a}$ & 14.3 & $14.6 \mathrm{~b}$ & $13.6 \mathrm{ab}$ & 0.40 & 0.40 & 0.34 & 0.29 & $0.46 \mathrm{~b}$ \\
\hline Irr3 & 78.4 & 88.5 & 82.5 & 81.1 & $74.3 \mathrm{~b}$ & 62 & 55 & $41 \mathrm{a}$ & 14.0 & $14.6 \mathrm{~b}$ & $13.0 \mathrm{~b}$ & 0.37 & 0.42 & 0.37 & 0.29 & $0.45 \mathrm{~b}$ \\
\hline $\operatorname{Irr} 4^{y}$ & 79.6 & 86.6 & 84.8 & 89.1 & $79.6 \mathrm{a}$ & 67 & 51 & $32 \mathrm{~b}$ & 14.1 & $16.5 \mathrm{a}$ & $14.2 \mathrm{a}$ & 0.37 & 0.38 & 0.35 & 0.32 & $0.49 \mathrm{a}$ \\
\hline Significance & NS & & & & $* * *$ & NS & NS & $* * * *$ & NS & $* * * *$ & $*$ & NS & & & & $* *$ \\
\hline $\begin{array}{l}\mathrm{C} \times \mathrm{I} \text { interaction } \\
\mathrm{SE} \text { interaction }\end{array}$ & NS & & $\begin{array}{l}* \\
1.7\end{array}$ & & NS & NS & NS & NS & NS & NS & NS & NS & & $\begin{array}{c}* * \\
0.1\end{array}$ & & NS \\
\hline
\end{tabular}

Irr1: 100\% evapotranspiration (ET) both sides daily; Irr2: 50\% ET both sides daily; Irr3: 50\% ET one side daily; Irr4: every two days, both sides at 50\% ET (2007), $25 \%$ ET (2008), and 18\% ET (2009).

NS, *,**,***,****Nonsignificant or means significantly different at $P=0.05,0.01,0.001$, or 0.0001 , respectively.

${ }^{\mathrm{z}}$ Low crop load targeted at $2.5,3$, and 3.75 fruit $/ \mathrm{cm}^{2}$ TCSA, 2007-09, respectively; medium crop load at 4.5, 6, and 7.5 fruit/cm ${ }^{2}$ TCSA, 2007-09, and high crop load target at 9,12 , and 15 fruit $/ \mathrm{cm}^{2}$ TCSA, 2007-09.

${ }^{y}$ Irrigation for this treatment reduced to 25\% ET (2008) and 18\% ET (2009).

when deficit irrigation was most severe (Irr4, $18 \%$ ET) in the last year of the study.

\section{Conclusions}

Soil moisture contents responded to the amount of water applied per irrigation treatment except during the occasional intense summer storms, which eliminated differences among irrigation treatments for about a week. Low stem water potential values occurred at soil water potentials much above the permanent wilting point $(-1500 \mathrm{kPa})$, suggesting high-threshold soil moisture contents around $15 \%(-20 \mathrm{kPa})$ for avoiding moderate plant water stress $(<-1.5 \mathrm{MPa})$ and around $10 \%(-100 \mathrm{kPa})$ for avoiding severe plant water stress $(<-2.0 \mathrm{MPa})$.

Negative effects of low soil moisture due to imposed water deficits on plant water status were offset by reducing crop load. At full irrigation (100\% ET replacement), the optimum crop load for 'Ambrosia' apple, defined as producing an average fruit size of $200 \mathrm{~g}$, was 8 fruit $/ \mathrm{cm}^{2}$ TCSA Under these conditions, seasonal average midday stem water potential was greater than $-1.5 \mathrm{MPa}$. Water applications at 50\% ET replacement in the first year reduced fruit size sufficiently that crop load reductions to 7 fruit $/ \mathrm{cm}^{2}$ TCSA were required to maintain a $200 \mathrm{~g}$ average size when water was applied either every second day or daily to one side of the tree and to 6.25 fruit $/ \mathrm{cm}^{2}$ TCSA when applied to both sides of the tree. However, beyond the first year, midday stem water potentials began to reflect more closely the amount of water applied with minimum values approaching and below $-2.0 \mathrm{MPa}$ late in the growing season when water applications were less than $50 \%$ ET replacement. If water applications were reduced to $18 \%$ ET replacement, it was not possible to adjust crop load to maintain an average fruit size of $200 \mathrm{~g}$.

The benefits of crop load reduction on fruit size manifested soon after imposition of the treatment, whereas size reduction associated with deficit irrigation occurred later in the growing season during maximum evaporative demand. Generally, reducing crop load has few other negative effects on fruit quality since firmness and SSC increased while fruit disorders, other than core at harvest, were not increased. However, there are some important limitations to depending on crop reduction to overcome reduced water applications. Reducing water supply early in the growing season post bloom during cell division is undesirable due to serious reductions in fruit size that can occur and cannot be overcome by subsequent crop reduction. This is also usually a time of lower air temperatures and evaporative demand when lower water savings are possible when irrigating according to ET. Furthermore, extreme reductions in water application, as in this study at $18 \%$ to $25 \%$ ET replacement, create conditions where it is not possible to reduce crop sufficiently to result in reasonable fruit size or quality.

\section{Literature Cited}

Allen, R.G., L.S. Pereira, D. Raes, and M. Smith. 1998. Crop evapotranspiration guidelines for computing crop water requirements. FAO Irrigation and Drainage Paper 56. United Nations Food and Agriculture Organization, Rome, Italy.

Barnett, T., R. Malone, W. Pennell, D. Stammer, B. Semtner, and W. Washington. 2004. The effects of climate change on water resources in the west: Introduction and overview. Clim. Change 62:1-11.

Behboudian, M.H. and T.M. Mills. 1997. Deficit irrigation in deciduous orchards. Hort. Rev. 21:105-131.

Ebel, R.C., E.L. Proebsting, and M.E. Patterson. 1993. Regulated deficit irrigation may alter apple maturity, quality and storage life. HortScience 28:141-143.

Girona, J., J. Marsal, M. Mata, A. Arbones, and T.M. DeJong. 2004. A comparison of the combined effect of water stress and cropload on fruit growth during different phenological stages in young peach trees. J. Horti. Sci. Biotechnol. 79:308-315.

Hansen, P. 1973. The effect of cropping on the growth and uptake of nutrients by apple trees at different levels of nitrogen, potassium, magnesium and phosphorus. Acta Agr. Scandinavica 23:87-92.

Hillel, D. 2004. Introduction to environmental soil physics. Elsevier Academic Press, New York, NY.
Lakso, A.N. 2014. Comparing water use efficiency of apples and grapes - physiological and morphological aspects. Acta Hort. 1038:67-72.

Landsberg, J.J. and H.G. Jones. 1981. Apple orchards, p. 419-469. In: T. Kozlewosli (ed.). Water deficits and plant growth, Vol VI. Academic Press, New York, NY.

Leib, B., H. Caspari, C. Redulla, P. Andrews, and J. Jabro. 2006. Partial rootzone drying and deficit irrigation of 'Fuji' apples in a semi-arid climate. Irr. Sci. 24:85-99.

Marsal, J., M. Nata, A. Arbones, J. del Campo, J. Girona, and G. Lopez. 2008. Factors involved in alleviating water stress by partial crop removal in pear trees. Tree Physiol. 28:1375-1382.

McCutchan, H. and K.A. Shackel. 1992. Stemwater potential as a sensitive indicator of water stress of prune trees (Prunus domestica L. cv. French). J. Amer. Soc. Hort. Sci. 117:607-611.

Mills, T.M., M.H. Behboudian, and B.E. Clothier. 1996. Water relations, growth, and the composition of 'Braeburn' apple fruit under deficit irrigation. J. Amer. Soc. Hort. Sci. 121:286-291.

Mote, P.W., A.F. Hamlet, M.P. Clark, and D.P. Lettenmaier. 2005. Declining mountain snowpack in western North America. Bull. Amer. Meteorol. Soc. 86:39-49.

Mpelasoka, B.S., M.H. Behboudian, J. Dixon, S.M Neal, and H.W. Caspari. 2000. Improvement of fruit quality and storage potential of 'Braeburn' apple through deficit irrigation. J. Hort. Sci. Biotechnol. 75:615-621.

Mpelasoka, B.S., M.H. Behboudian, and S. Ganesh. 2001. Fruit quality attributes and their interrelationships of 'Braeburn' apple in response to deficit irrigation and crop load. Gartenbauwissenschaft 66:247-253.

Naor, A. 2006. Irrigation scheduling and evaluation of tree water status in deciduous orchards. Hort. Rev. 32:111-165.

Naor, A. 2014. Crop load and irrigation interactions - a new dimension of RDI. Acta Hort. 1038:113-119.

Naor, A., S. Naschitz, M. Peres, and Y. Gal. 2008. Response of apple fruit size to tree water status and crop load. Tree Physiol. 28:1255-1261.

Neilsen, G.H., D. Neilsen, and L. Herbert. 2009. Nitrogen fertilization and timing of application affect nitrogen nutrition, yield, firmness, and color of apples grown at high density. HortScience 44:1425-1431. 
Neilsen, D., G.H. Neilsen, L. Herbert, and S. Guak. 2010. Effect of irrigation and crop load management on fruit nutrition and quality for Ambrosia/M.9 apple. Acta Hort. 868:63-72.

Neilsen, G.H., D. Neilsen, F. Kappel, and T. Forge. 2014. Interaction of irrigation and soil management on sweet cherry productivity and fruit quality at different crop loads that simulate those occurring by environmental extremes. HortScience 49:215-220.

Neilsen, G.H., D. Neilsen, and F. Peryea. 1999. Response of soil and irrigated fruit trees to fertigation or broadcast application of nitrogen, phosphorus, and potassium. HortTechnology 9:393-401.

Neilsen, G.H., P. Parchomchuk, R. Berard, and D. Neilsen. 1997. Irrigation frequency and quantity affect root and top growth of ferigated 'McIntosh' on M.9, M.26, and M.7 rootstock. Can. J. Plant Sci. 77:133-139.

Neilsen, D., C.A.S. Smith, G. Frank, W. Koch, Y. Alila, W.S. Merritt, W.G. Taylor, M. Barton, J.W. Hall, and S.J. Cohen. 2006. Potential impacts of climate change on water availability for crops in the Okanagan Basin, British Columbia. Can. J. Soil Sci. 86:921-936.

Palmer, J.W., R. Giuliani, and H.M. Adams. 1997. Effect of crop load on fruiting and leaf photosynthesis of 'Braeburn'/M.26 apple trees. Tree Physiol. 17:741-746.

Parchomchuk, P., R.C. Berard, and T.W. van derGulik. 1996. Automatic irrigation scheduling using an electronic atmometer, p. 1099-1104. In: C.R. Camp, E.J. Sadler, and R.E. Yoder (eds.). Evapotranspiration and irrigation scheduling. Amer. Soc. Agr. Engn. Proc. Intl. Conf. San Antonio, TX.

Proebsting, E.J., Jr., and J.E. Middleton. 1980. The behavior of peach and pear trees under extreme drought stress. J. Amer. Soc. Hort. Sci. 105:380-385.

SAS. 2006. SAS for mixed models. 2nd ed. SAS Inst., Cary, NC.

Topp, G.C. and W.D. Reynolds. 1998. Time domain reflectometry: A seminal technique for measuring mass and energy in soil. Soil Tillage Res. 47:125-132.

Volz, R.K., I.B. Ferguson, J.H. Bowen, and C.B. Watkins. 1993. Crop load effects on fruit mineral nutrition, maturity, fruiting and tree growth of 'Cox's Orange Pippin' apple. J. Hort. Sci. 68:127-137.

Whitfield, P.H. and A.J. Cannon. 2000. Recent variations in climate and hydrology of British Columbia and Yukon. IHP-V technical documents in hydrology 33. UNESCO, Paris, France.

Wittneben, U. 1986. Soils of the Okanagan and Similkameen Valleys. Ministry of the Environment Technical Report 10. British Columbia Soil Survey. Report 52, Victoria, BC, Canada. Wünsche, J.N. and I.B. Ferguson. 2005. Crop load interactions in apple. Hort. Rev. 31:231-290.

Yuri, J.A., G. Gonzalez Talice, J. Verdugo, and A. del Pozo. 2011. Response of fruit growth, quality and productivity to crop load in apple cv. Ultra Red Gala/MM111. Sci. Hort. 127:305-312. 